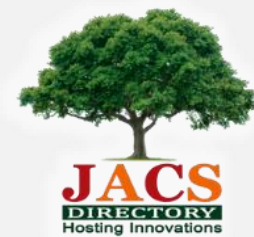

Journal of Nanoscience and Technology

\title{
Synthesis and Characterization of Nanosize Polyanthranillic Acid for Solid Polymer Electrolyte
}

\author{
R. Kirupagaran ${ }^{1,2}$, C. Vedhi ${ }^{3, *}$ \\ ${ }^{1}$ Research Scholar (Reg. No.: 11941), PG and Research Department of Chemistry, V.O. Chidambaram College affiliated to Manonmaniam Sundaranrar \\ University, Abishekapatti - 627 012, Tirunelveli, India. \\ ${ }^{2} P G$ \& Research Department of Chemistry, Govt. Arts College, Dharmapuri - 636 705, Tamilnadu, India. \\ ${ }^{3} P G$ \& Research Department of Chemistry, V.O. Chidambaram College, Thoothukudi - 628 008, Tamilnadu. India.
}

\section{ARTICLE DETAILS}

Article history:

Received 20 March 2019

Accepted 29 April 2019

Available online 05 June 2019

\section{Keywords:}

Polyanthranilic Acid

Pseudocapacitors

Energy Density

\begin{abstract}
A B S T R A C T
Conducting polymer of anthranilic acid (PANA) has been synthesized through emulsion polymerization technique. Emulsion polymerization helps in slowing down kinetics of polymerization in comparison to one-phase polymerization and thereby induces formation of monodispersed. Reaction progress of conducting polymer formation is studied by UV-Vis and FTIR spectroscopy. Morphology of PANA is characterized by XRD, TEM, AFM and electrochemical techniques. XRD of conducting polymer depicts the less crystalline nature of polymer with crystallite size of $75 \mathrm{~nm}$. Voltammetry has shown the electroactive nature of PANA. The performance of energy storage devices including pseudocapacitors is evaluated mostly by measuring energy density and power density.
\end{abstract}

\section{Introduction}

Conducting polymers have gained increasing attention owing to their strong potential as alternatives to their inorganic counterparts, leading to significant fundamental and practical research efforts for the past several decades. Conducting polymers provide the advantages of chemical diversity, low density, flexibility, corrosion resistance, easy-to-control shape and morphology, and tunable conductivity over their existing inorganic counterparts $[1,2]$. Successful preparations of conducting polymers composites with high mechanical stabilities, flexibilities, and conductivities have proven that conducting polymers can serve as key material components in light emitting diodes [3,4], transistors [5], electrochromic devices [6,7], actuators [8], electrochemical capacitors $[9,10]$, photovoltaic cells $[11,12]$, and sensors $[13,14]$. Conducting polymer-modified electrodes have been widely investigated because of their potential applicationin areas such as electrocatalysis [15], sensors [16], corrosion [17], batteries [18], electronic displays, and devices [19].

In this paper, are interested in performing a synthesis and characterization of solid nanosize polyanthranillic acid electrolyte for batteries application.

\section{Experimental Methods}

\subsection{Materials}

The chemicals o-aminobenzoic acid (Aldrich), hydrochloric acid, potassium per sulphate, were used as such. The electrodes lead, zinc, stainless steel and copper were purchased from E-Merck.

\subsection{Synthesis of Polyanthranilic Acid}

The monomer of anthranilic acid was dissolved in $0.1 \mathrm{M}$ hydrochloric acid and solution of potassium per sulphate was added slowly into the monomer. The solution was kept stirring for about $3 \mathrm{~h}$ at room temperature, it was then left overnight in the refrigerator. Then the obtained brownish black powder was filtered, dried and was found to be soluble in dimethyl sulphoxide, N-methyl pyrrolidine, diethylene glycol and sodium hydroxide which give reddish brown solutions.

\subsection{Characterizations}

The solution of the polymer in dimethyl sulphoxide was used for recording the UV-VIS spectra. For recording the UV-Vis absorption spectra, a computer controlled JascoV-650 spectrophotometer was used. The FT-IR spectra were recorded using a Thermo scientific instrument. The X-ray diffraction (XRD) patterns were recorded for the powdered materials using a BRUKER (D8 ADVANCE) X-ray diffractometer. The electrochemical studies were carried out using electrochemical workstation (mode 650C), CH-Instrument Inc., TX, USA. The cyclic voltammetry studies were carried out in a three-electrode cell. Pt was used as counter electrode and silver-silver chloride electrode as reference electrode.

\section{Results and Discussion}

\subsection{Spectral Characterization}

UV-Vis absorption spectra of synthesized polymer were carried out range from $900 \mathrm{~nm}$ to $200 \mathrm{~nm}$. Three peaks around at $284 \mathrm{~nm}, 380 \mathrm{~nm}$ and $625 \mathrm{~nm}$ was observed for polyanthranilic acid by UV-Vis spectra as present in Fig. 1. The peak at $284 \mathrm{~nm}$ is attributed to the л-л* transition for the benzenoid ring, the band at $380 \mathrm{~nm}$ for quinoid rings and $625 \mathrm{~nm}$ for polaronic transition due to the polymer. This is in good agreement with the results reported earlier [20]. The band gap energy value can be obtained from the curve of absorption vs energy $(\mathrm{eV})$ as shown in the Fig. 2 and the value is $2.87 \mathrm{eV}$.

Fig. 3 exhibits the FTIR spectra of polyanthranilic acid. The characteristic bands appeared for polyanthranilic acid shows at $3231 \mathrm{~cm}^{-}$ ${ }^{1}$ due to $\mathrm{N}-\mathrm{H}$ stretching, $2615 \mathrm{~cm}^{-1}$ illustrate $\mathrm{O}-\mathrm{H}$ stretching, $1691 \mathrm{~cm}^{-1}$ presence of $\mathrm{C}=0,1558 \mathrm{~cm}^{-1}$ due to quinoid $\mathrm{C}=\mathrm{C}$ stretching, $1506 \mathrm{~cm}^{-1}$ appeared for benzenoid $\mathrm{C}=\mathrm{C}$ stretching, $1450 \mathrm{~cm}^{-1}$ was stretching of aromatic ring, $1373 \mathrm{~cm}^{-1}$ peak for $\mathrm{C}-\mathrm{N}$ stretching for secondary aromatic amine, $1247 \mathrm{~cm}^{-1}$ carried out $\mathrm{C}-\mathrm{H}$ stretching, $1166 \mathrm{~cm}^{-1}$ peak due to $\mathrm{N}=\mathrm{Q}=\mathrm{N}$ stretching, $\mathrm{Q}=$ quinoid ring, $1081 \mathrm{~cm}^{-1}$ and $1045 \mathrm{~cm}^{-1}$ are attribute aromatic $\mathrm{C}-\mathrm{H}$ in plane bending, $821 \mathrm{~cm}^{-1}$ and $756 \mathrm{~cm}^{-1} \mathrm{C}-\mathrm{H}$ out of plane bending and confirms 1,4 disubstituted benzene ring. 


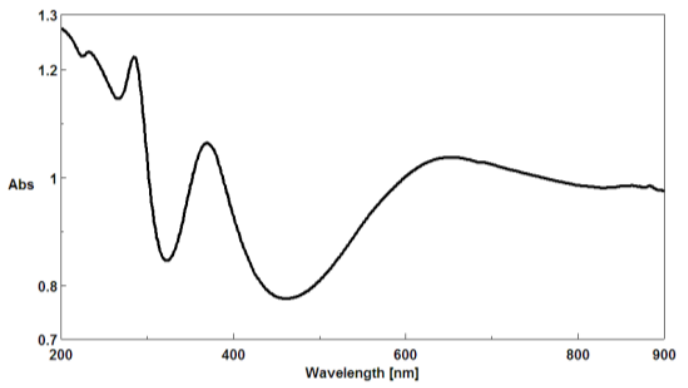

Fig. 1 UV-Vis behavior of synthesised polyanthranillic acid

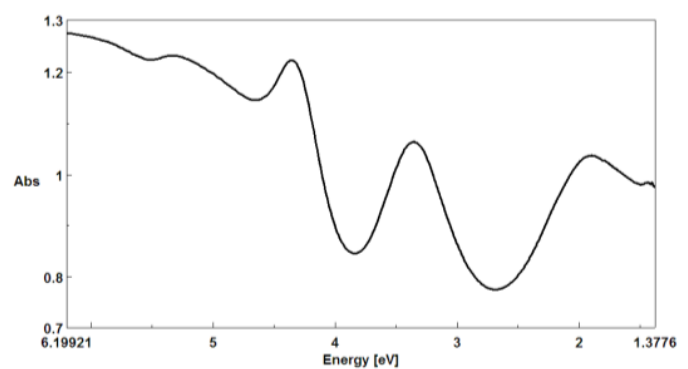

Fig. 2 Band gap energy curve of synthesised polyanthranillic acid

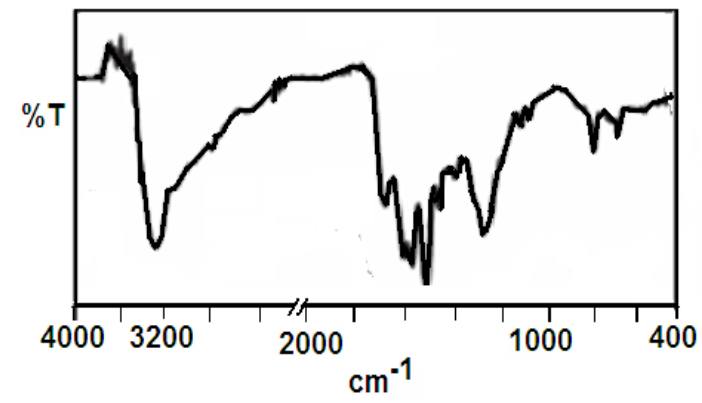

Fig. 3 FTIR behaviour of synthesised polyanthranillic acid

\subsection{Morphological Behaviour}

In general X-ray diffraction pattern of amorphous polymer will not show any sharp and highly intense peaks whereas the nanocomposites of amorphous polymer show sharp and highly intense peaks. This is due to the development of crystallinity in the amorphous polymer. The X-ray powder diffraction patterns for the polymers of o-amino benzoic acid as in Fig. 4 are typical of semi crystalline polymers. Polymers with high crystallinity usually show higher conductivity. The particle size was calculated using Scherrer equation and found as $75 \mathrm{~nm}$.

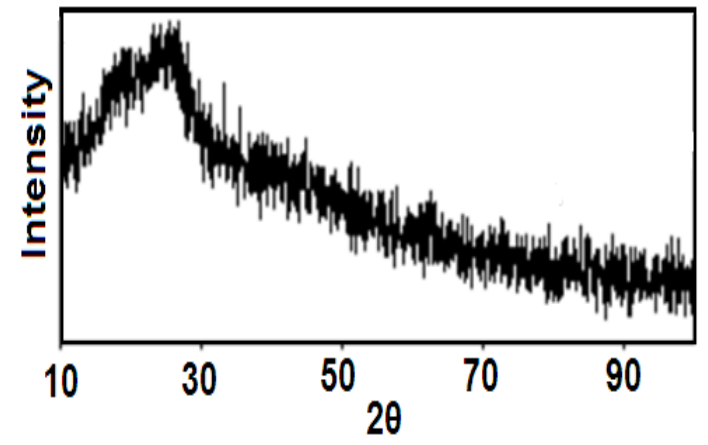

Fig. 4 XRD studies Polyanthranillic acid

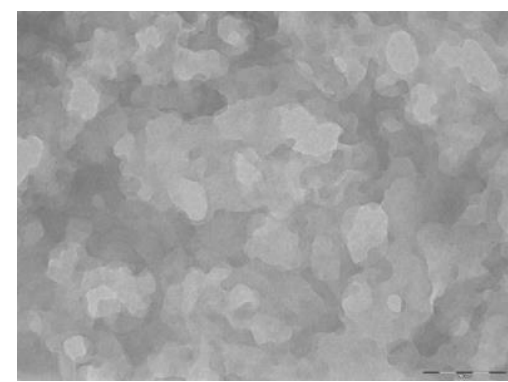

Fig. 5 TEM behavior of synthesised polyanthranillic acid https://doi.org/10.30799/jnst.S13.19050307
TEM image of polyanthranilic acid also support the nano size materials. Morphology of polymeric materials shows expanded globules is not very uniform because of the strong oxidizing nature as given in Fig. 5. AFM image of a thin film of polyanthranilic acid shows uniform fiber depicting the presence of nanosize polymeric matrix, as present in Fig. 6, with average surface roughness $74 \mathrm{~nm}$.
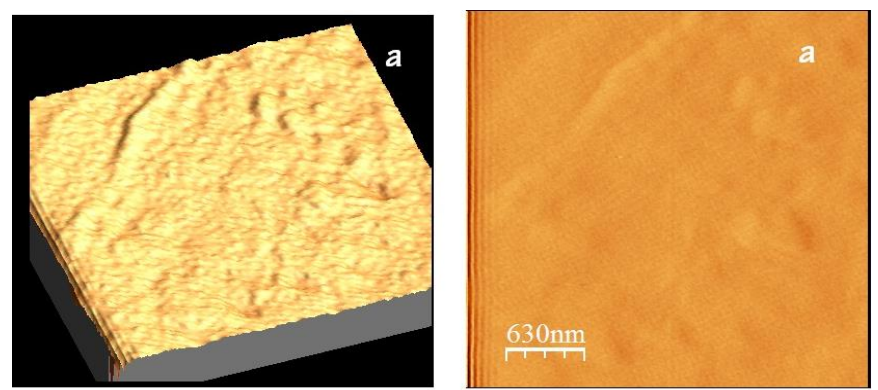

Fig. 6 AFM behavior of synthesised polyanthranillic acid

\subsection{Electrochemical Studies}

Polyanthranilic acid was coated on GCE and used as working electrode. Cyclic voltammogram of polyanthranilic acid were recorded by potential cycling the between $-0.6 \mathrm{~V}$ and $1.0 \mathrm{~V}$ in $0.1 \mathrm{~N} \mathrm{HCl}$ as shown in Fig. 7. One anodic and broad cathodic peak was appeared for polyanthranilic acid. The oxidation around at $0.4 \mathrm{~V}$ presents of amine in aromatic ring and corresponding reduction at $0.2 \mathrm{~V}$ the redox process is quasi reversible. As the scan rate increases the peak current, nanosize polyanthranilic acid also increased linearly which is indicating an adherent film on stainless steel. This was further confirmed by a straight-line graph obtained by plotting peak current vs scan rate.

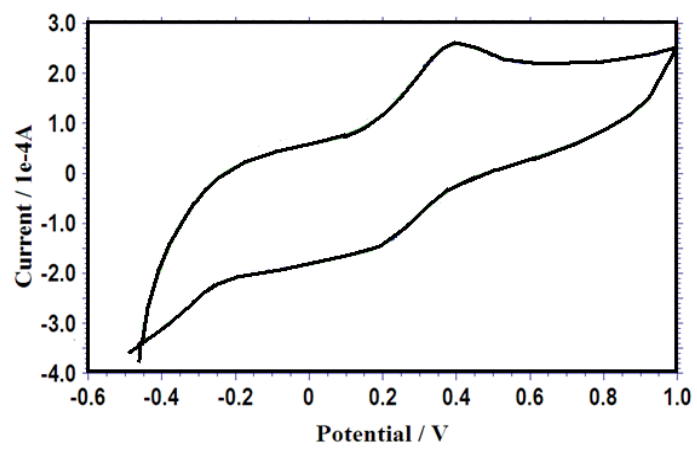

Fig. 7 Cyclic voltammetric behavior of synthesised polyanthranillic acid

The electrochemical behaviour of, cyclic voltammetry performed in a two-electrode cell to determine the pseudocapacitors. Under redox cycles, the specific capacitance is obtained from cyclic voltammetry curves according to the following equation,

$$
C=\frac{1}{m v\left(V_{b}-V_{a}\right)} \int_{b}^{a} i d V
$$

where $\mathrm{i}$ is the discharge current corresponding to the reduction or oxidation peak, $v$ is the potential scan rate, $m$ is the mass of deposited material, and $V_{a}$ and $V_{b}$ are the high and low potential limits of the cyclic voltammetry studies, respectively. The long-term cycle stability is a significant challenge for high-performance pseudocapacitors based on conducting polymers. Conversely, the performance of energy storage devices including pseudocapacitors is evaluated mostly by measuring energy density and power density. The energy density is the maximum energy that a device of a given size or mass can store. The power density measures how quickly the battery can deliver energy for a given size. The power density (P) and energy density (E) of a conducting polymer electrode material are normally derived from galvanostatic charge/discharge cycles and can be calculated using the following equations, $\mathrm{E}=0.5 \mathrm{C} \Delta \mathrm{V}^{2} ; \mathrm{P}=\mathrm{E} / \Delta \mathrm{t}$, where $\mathrm{C}=\mathrm{i} \Delta \mathrm{t} / \mathrm{m} \Delta \mathrm{V}$ is the specific capacitance derived from galvanostatic tests, $\Delta \mathrm{t}$ is the discharge time, and $\Delta \mathrm{V}$ is the potential window (or the voltage range for two electrode cells). To enhance the power density and energy density of pseudocapacitors, it is very important to maximize the specific capacitance and potential window. Currently, most studies are focused on developing advanced materials to improve the conductivity, charge/discharge rate, effective surface area, and redox capability of pseudocapacitors. The value of specific capacitance, energy density and power density are $235 \mathrm{Fg}^{-1}, 300.8$ $\mathrm{WhKg}^{-1}$ and $9.4 \mathrm{WKg}^{-1}$ respectively. 
A chemically prepared conducting polymer was used as solid polymer electrolyte. The electrolyte fixed in between of two electrode materials like $\mathrm{Pb}$ as anode and $\mathrm{Cu}, \mathrm{Zn}, \mathrm{SS}$ and $\mathrm{Pb}$ used as cathode (Fig. 8). The currenttime curve shows the continuous constant current responds of polymer electrolyte.

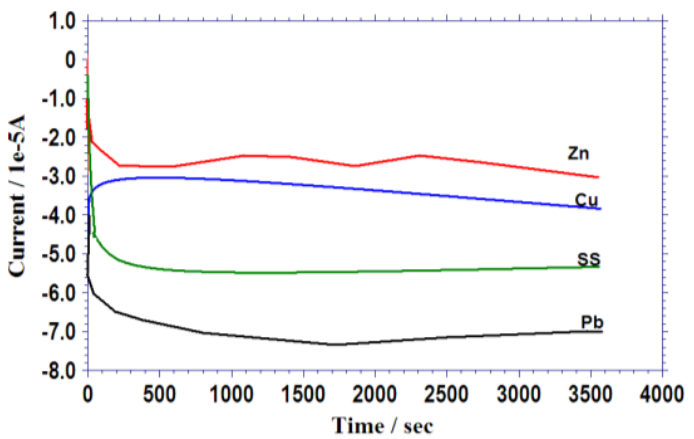

Fig. 8 Current vs Time curve of synthesised polyanthranillic acid on $\mathrm{Pb}$ anode and $\mathrm{Zn}$, $\mathrm{Cu}, \mathrm{SS}, \mathrm{Pb}$ as cathode

The OCP measurements indicate that the stages of polyanthranilic acid solid electrolyte described by a sequence of reactions involving oxidation and coupling reactions at the $\mathrm{Pb}$ with solid polymer electrolyte interface. The potential time curves of the chemically synthesized polymer electrolyte are shown in Fig. 9. In fact, the behaviour of the synthesized polymer electrolyte overshoot during the first few seconds probably indicates difficult formation of dimmers and oligomers. After this, potential remains constant suggesting that building up of the film proceeds according to the same reaction along the full thickness of the polymer.

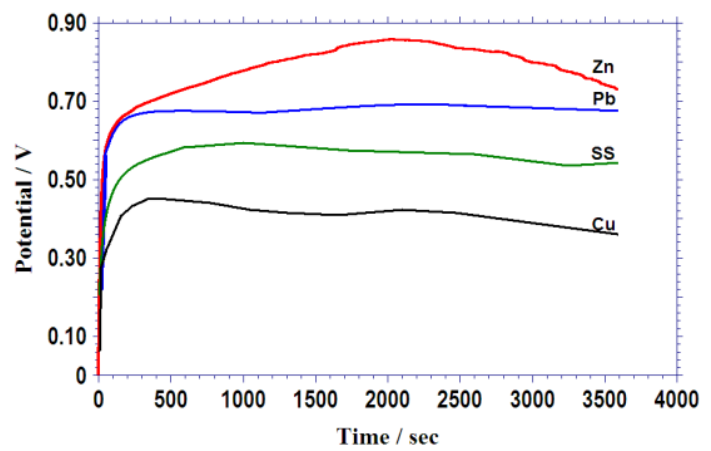

Fig. 9 Potential vs Time curve of synthesised polyanthranillic acid on $\mathrm{Pb}$ anode and $\mathrm{Zn}, \mathrm{Cu}, \mathrm{SS}, \mathrm{Pb}$ as cathode

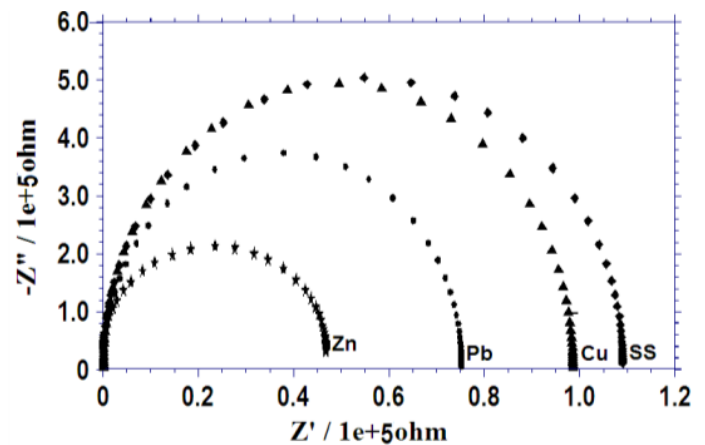

Fig. 10 Electrochemical impedence behaviour of synthesised polyanthranillic acid on $\mathrm{Pb}$ anode and $\mathrm{Zn}, \mathrm{Cu}, \mathrm{SS}, \mathrm{Pb}$ as cathode

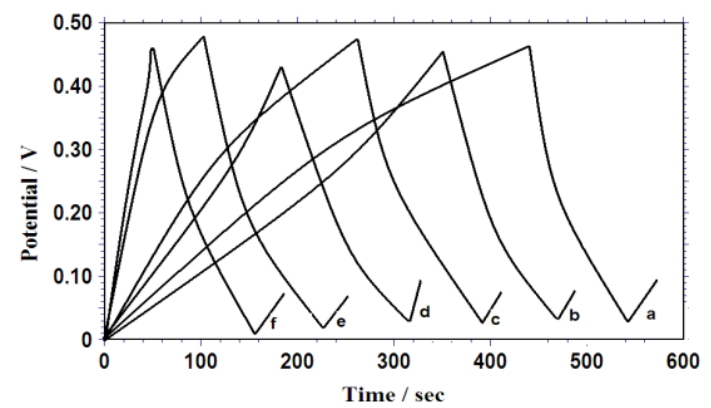

Fig. 11 Charge and discharge curve of synthesised polyanthranillic acid at different current density a) $2 \mathrm{~mA} \mathrm{b)} 4 \mathrm{~mA}$ c) $6 \mathrm{mAd}$ ) $8 \mathrm{~mA}$ e) $10 \mathrm{~mA}$ and f) $12 \mathrm{~mA}$

\subsection{EIS Studies}

Polymer electrolyte of polyanthranillic acid fixed in between of $\mathrm{Pb}$ anode and $\mathrm{Cu}, \mathrm{Pb}, \mathrm{SS}$ and $\mathrm{Zn}$ plate used as cathode electrodes. Electrochemical impedance measurements were carried over a frequency range between $100 \mathrm{KHz}$ and $0.01 \mathrm{~Hz}$ at after fixed open circuit potential. The studies illustrate simple equivalent Randle circuit. The presence of a single semi-circle (Fig. 10) shows the solid electrolyte acts as a barrier. It is seen that introduction of metal atom increases the values of $R_{c t}$ and reduces the $\mathrm{C}_{\mathrm{dl}}$. The charge transfer resistance $\left(\mathrm{R}_{\mathrm{ct}}\right)$ value is low $\left(40 \Omega \mathrm{cm}^{2}\right)$, whereas for the nanopolymer solid electrolyte it is high. Also, the decrease in $\mathrm{C}_{\mathrm{dl}}$ is attributed to increase in thickness of electronic double layer. The increase in $R_{c t}$ value is attributed to the formation of protective film on the metal/solid polymer electrolyte interface. These observations suggest that polyanthranillic acid composites solid electrolyte function by adsorption at metal surface thereby causing the decrease in $\mathrm{C}_{\mathrm{dl}}$ values and increase in $\mathrm{R}_{\mathrm{ct}}$ values. A good barrier allows very little current flow showing high resistance during impedance measurements. The charge transfer resistance $\left(R_{c t}\right)$ and the interfacial double layer capacitance $\left(C_{d l}\right)$ derived from these curves. The device exhibited double layer capacitance values between $305 \mathrm{Fg}^{-1}$ and $248 \mathrm{Fg}^{-1}$.

The capacitor was tested by charge-discharge cycles to estimate the changes in the capacitance values and also the stability of the electrode material. Fig. 11 shows the charge-discharge curves for current density was varied between $2 \mathrm{mAcm}^{-2}$ and $12 \mathrm{mAcm}^{-2}$. The capacitor value exhibited between $254 \mathrm{Fg}^{-1}$ and $80 \mathrm{Fg}^{-1}$. The decrease of capacitance is due to increase in the resistance values of the electrode materials after repeated doping-dedoping processes. The stability of the electrode was tested by charge-discharge. The increase in capacitance values at lower current densities. The lower values are mainly due to the over-oxidation of polymer formed by the use of the strong oxidizing agent.

\section{Conclusion}

Chemically synthesis of conducting polyanthranilic acid was successfully carried out in this research work. The characterization of the chemically synthesized conducting polyanthranilic acid was done by using UV-Vis and FTIR studies. The first (shoulder) about at $284 \mathrm{~nm}$ is attributed to the $л-\Omega^{*}$ transition for the benzenoid ring, the band at $380 \mathrm{~nm}$ for quinoid rings and $625 \mathrm{~nm}$ for polaronic transition due to the emeraldine state of the polymer. CV studies revealed an adherent film on GC electrode. The value of specific capacitance, energy density and power density are $235 \mathrm{Fg}^{-1}, 300.8 \mathrm{WhKg}^{-1}$ and $9.4 \mathrm{WKg}^{-1}$ respectively. TEM studies show a mixed crystalline and amorphous morphology. The device exhibited double layer capacitance values between $305 \mathrm{Fg}^{-1}$ and $248 \mathrm{Fg}^{-1}$.

\section{Acknowledgement}

The authors are thankful to Department of Science and Technology (Fast Track), New Delhi for using electrochemical workstation and UGC New Delhi for AEM and FTIR spectroscopy at V.O. Chidambaram College. One of the author R. Kirupagaran thankful to UGC Hyderabad for the financial assistance.

\section{References}

[1] N. Hall, Twenty-five years of conducting polymers, Chem. Commun. 7 (2003) 1 4.

[2] Thanh-Hai Le, Yukyung Kim, Hyeonseok Yoon, Electrical and electrochemical properties of conducting polymers, Polymers 9 (2017) 150-182.

[3] O.L. Gribkova, O.D. Omelchenko, A.R. Tameev, D.A. Lypenko, A.A. Nekrasov, et al., The specific effect of graphene additives in polyaniline-based nanocomposite layers on performance characteristics of electroluminescent and photovoltaic devices, High Energy Chem. 50 (2016) 134-138.

[4] P. Biju, X. Jining, K.A. Jose, K.V. Vijay, A new synthetic route to enhance polyaniline assembly on carbon nanotubes in tubular composites, Smart Mater. Struct. 13 (2004) 105-108.

[5] H. Tang, P. Kumar, S. Zhang, Z. Yi, G.D. Crescenzo, et al., Conducting polymer transistors making use of activated carbon gate electrodes, ACS Appl. Mater. Interf. 7 (2015) 969-973.

[6] L. Zhao, L. Zhao, Y. Xu, T. Qiu, L. Zhi, G. Shi, Polyaniline electrochromic devices with transparent graphene electrodes, Electrochim. Acta 55 (2009) 491-497.

[7] K.Y. Shen, C.W. Hu, L.C. Chang, K.C. Ho, A complementary electrochromic device based on carbon nanotubes/conducting polymers, Sol. Energy Mater. Sol. Cells 98 (2012) 294-299.

[8] J.C. García-Gallegos, I. Martín-Gullón, J.A. Conesa, Y.I. Vega-Cantú, F.J. Rodríguez-Macías, The effect of carbon nanofillers on the performance of electromechanical polyaniline-based composite actuators, Nanotech. 27 (2016) 015501:1-11. 
[9] X. Jiang, S. Setodoi, S. Fukumoto, I. Imae, K. Komaguchi, et al., An easy one-step electrosynthesis of graphene/polyaniline composites and electrochemical capacitor, Carbon 67 (2014) 662-672.

[10] M.A. Memon, W. Bai, J. Sun, M. Imran, S.N. Phulpoto, et al., Conjunction of conducting polymer nanostructures with macroporous structured graphene thin films for high-performance flexible supercapacitors, ACS Appl. Mater. Interf. 8 (2016) 11711-11719.

[11] J. Lee, H. Kang, S. Kee, S.H. Lee, S.Y. Jeong, et al., Long-term stable recombination layer for tandem polymer solar cells using self-doped conducting polymers, ACS Appl. Mater. Interf. 8 (2016) 6144-6151.

[12] E.M.J. Johansson, L. Yang, E. Gabrielsson, P.W. Lohse, G. Boschloo, L. Sun, A. Hagfeldt, Combining a small hole-conductor molecule for efficient dye regeneration and a hole-conducting polymer in a solid-state dye-sensitized solar cell, J. Phys. Chem. C 116 (2012) 18070-18078.

[13] J.Janata, M. Josowicz, Conducting polymers in electronic chemical sensors, Nat. Mater. 2 (200) 19-24.

[14] H. Yoon, Current trends in sensors based on conducting polymer nanomaterials, Nanomater. 3 (2013) 524-549.
[15] V. Selvaraj, M. Alagar, I. Hamerton, Nanocatalysts impregnated polythiophene electrodes for the electrooxidation of formic acid, Appl. Cat. B 73 (2007) 172 179.

[16] M. Boopathi, M.S. Won, Y.B. Shim, A sensor for acetaminophen in a blood medium using a $\mathrm{Cu}(\mathrm{II})$-conducting polymer complex modified electrode, Anal. Chim. Acta 512 (2004) 191-197.

[17] R. Hasanov, S. Bilgic, Monolayer and bilayer conducting polymer coatings for corrosion protection of steel in $1 \mathrm{M} \mathrm{H}_{2} \mathrm{SO}_{4}$ solution, Prog. Org. Coat. 64 (2009) 435-445.

[18] C.Y. Wang, G. Tsekouras, P. Wagner, S. Gambhir, C.O. Too, D. Officer, G.G. Wallace, Functionalised polyterthiophenes as anode materials in polymer/polymer batteries, Synth. Metal. 160 (2010) 76-82.

[19] B. Yin, C. Jiang, Y. Wang, M. La, P. Liu, W. Deng, Synthesis and electrochromic properties of oligothiophene derivatives, Synth. Metal. 160 (2010) 432-435.

[20] Irudaya Antonat Sophia, G. Gopu, C. Vedhi, Synthesis and characterization of poly anthranilic acid metal nanocomposites, Open J. Syn. Theory Appl. 1 (2012) $1-8$.

\section{About the Conference...}

"International Conference on Advanced Materials and Their Applications" has been convened by Dr. C. Vedhi, Assistant Professor, PG and Research Department of Chemistry, V.O. Chidambaram College, Thoothukudi at his designated venue on $27^{\text {th }}$ December 2018. 